
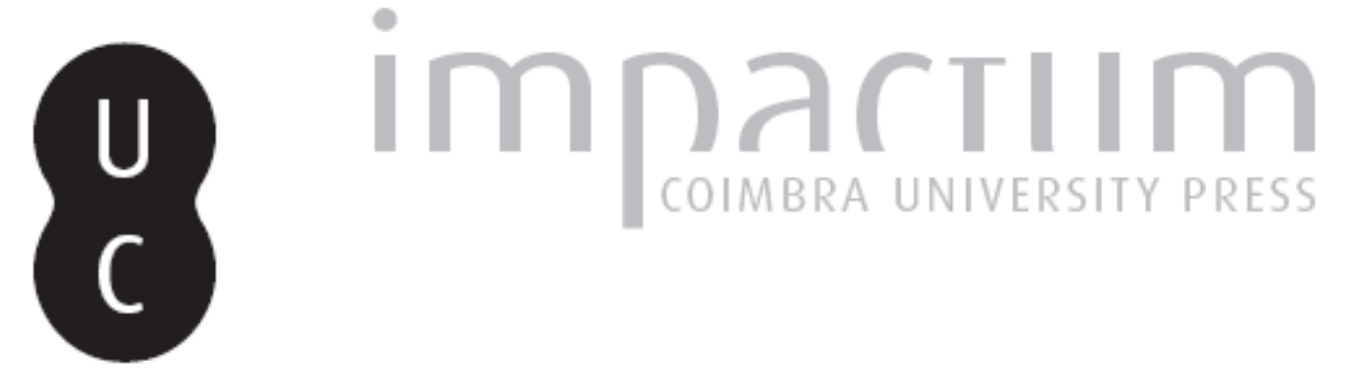

\title{
Shanghai: gueto e diáspora: documentário, ficção e testemunho
}

Autor(es): $\quad$ Fux, Jacques; Santos, Darlan Roberto dos

Publicado por: Imprensa da Universidade de Coimbra

URL persistente:

URl:http://hdl.handle.net/10316.2/43247

DOI:

DOI:https://doi.org/10.14195/0870-4147_48_11

Accessed : $\quad$ 26-Apr-2023 14:20:47

A navegação consulta e descarregamento dos títulos inseridos nas Bibliotecas Digitais UC Digitalis, UC Pombalina e UC Impactum, pressupõem a aceitação plena e sem reservas dos Termos e Condições de Uso destas Bibliotecas Digitais, disponíveis em https://digitalis.uc.pt/pt-pt/termos.

Conforme exposto nos referidos Termos e Condições de Uso, o descarregamento de títulos de acesso restrito requer uma licença válida de autorização devendo o utilizador aceder ao(s) documento(s) a partir de um endereço de IP da instituição detentora da supramencionada licença.

Ao utilizador é apenas permitido o descarregamento para uso pessoal, pelo que o emprego do(s) título(s) descarregado(s) para outro fim, designadamente comercial, carece de autorização do respetivo autor ou editor da obra.

Na medida em que todas as obras da UC Digitalis se encontram protegidas pelo Código do Direito de Autor e Direitos Conexos e demais legislação aplicável, toda a cópia, parcial ou total, deste documento, nos casos em que é legalmente admitida, deverá conter ou fazer-se acompanhar por este aviso.

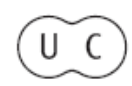




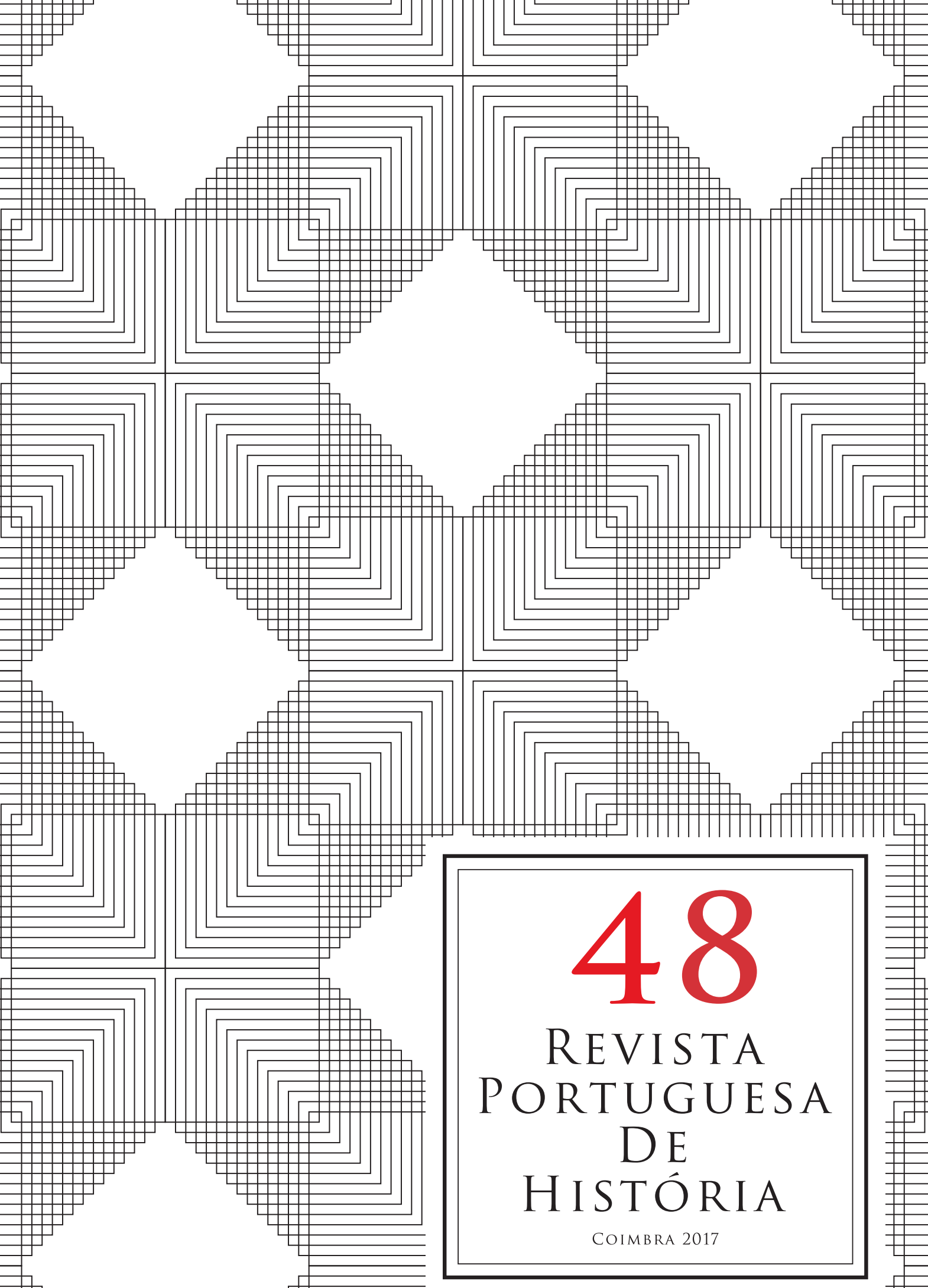




\title{
Shanghai: Gueto e diáspora. Documentário, ficção e testemunho
}

\section{Shanghai: Ghetto and diaspora. Documentary, fiction and testimony}

\author{
JACQUES FuX \\ Unicamp/Universidade Estadual de Campinas - Brasil \\ jacfux@gmail.com \\ Darlan Roberto dos SAntos \\ Faculdade Santa Rita (FaSaR/CL) \\ Faculdade de Direito de Conselheiro Lafaiete - Brasil \\ fenixdr@gmail.com
}

Texto recebido em/Text submitted on: 15/10/2016

Texto aprovado em/Text approved on: 05/04/2017

Resumo:

Este artigo tem como objetivo discutir a forma cinematográfica, artística e testemunhal dos filmes Shanghai Ghetto e Exil Shanghai. Apesar de ambos partirem dos testemunhos de ex-habitantes da comunidade judaica de Shanghai, a construção desses filmes/ documentários apresenta diversas nuances e trata diretamente com a questão artística e memorialística da representação limitada do testemunho na contemporaneidade.

Palavras-chave:

Shanghai Ghetto; Exil Shanghai; testemunho; ficção; memória; documentário.
Abstract:

This article discusses the cinematographic, artistic and testimonial form of the films Shanghai Ghetto and Exil Shanghai. Although both departure from testimonies made by ex-inhabitants of the Shanghai Jewish community, the construction of both present nuances illustrating the limitations to represent testimonies in contemporary times.

Keywords:

Shanghai Ghetto; Exil Shanghai; testimony; fiction; memory; documentary. 
A fotografia está lá fora, um objeto no mundo, e qualquer um, sempre (pelo menos em princípio),

Pode puxar um de seus fios e rastreá-lo de forma a reabrir a imagem E renegociar o que ela mostra, e até mesmo remodelando o que foi visto nela antes.. ${ }^{1}$

\section{Introdução}

A vida judaica em Shanghai data do início do século XIX. Vinda especialmente de Bombaim, a família Sasson, formada por prósperos comerciantes, enviou um de seus representantes, Elias David Sasson, em 1844, que foi responsável por construir um grande império comercial na cidade. Assim, em 1862, já existia uma pequena comunidade judaica formada principalmente por sefarditas ${ }^{2}$ dessa família. Estes permaneceram por lá até a ascensão do partido comunista na China, quando quase todos judeus partiram.

Logo após a guerra Russo-Japonesa, nos anos de 1904 e 1905, houve a segunda onda migratória de judeus para a China, chegando os primeiros judeus russos em Shangai. A maioria dos asquenazes, no entanto, desembarcou um pouco depois da revolução russa, em 1917.

Assim constituiu-se a comunidade judaica na cidade chinesa, até o fim dos anos 1930. Formada por comerciantes sefardins, que se deram muito bem nos negócios, e por uma comunidade mais religiosa, asquenazis, tal grupo mantinha ótimas relações com os habitantes dessa cidade. Apesar da pobreza e das péssimas condições de vida, em grande parte de Shangai, os judeus que lá viviam tinham muitas regalias e luxos, devido à sua privilegiada condição financeira. Entretanto, essa situação mudaria com a chegada de judeus fugidos da Alemanha e da Áustria, em 1938. Nesta época, Shanghai era o único lugar em que os judeus perseguidos poderiam se refugiar livremente.

1 "The photograph is out there, an object in the world, and anyone, always (at least in principle), can pull at one of its threads and trace it in such a way as to reopen the image and renegotiate what it shows, possibly even completely overturning what was seen in it before", William T. Vollmann, "Seeing eye to eye", BOOKFORUM, Fev/Mar 2009 (http://www. bookforum.com/inprint/015_05/3246, consultado em 2016.09.20).

${ }^{2}$ Sefardita vem do hebraico $\overline{1}$ (ידרפס/sefardi e se refere aos descendentes de Judeus originários de Portugal e da Espanha. 
Os dois filmes/documentários aqui trabalhados - Shanghai Guetto ${ }^{3}$ e Exil Shanghai ${ }^{4}$ - mostram, através de testemunhos e da utilização de imagens, a história dos judeus em Shanghai, explorando o papel da China no Holocausto. Ambos apresentam as três correntes migratórias que chegaram na China e discutem a visão particular de cada um dos grupos. Mas, talvez, o aspecto mais importante dos filmes seja a abordagem da exótica e salvadora jornada, da qual participaram quase vinte mil judeus da Europa, em busca de um lugar seguro.

O cinema tem a tendência de absorver imagens e sons de outras artes, como a fotografia, pintura, música, literatura, performance etc., mas pode, também, ser responsável por prejudicar o entendimento de todo o ecletismo e a rica polissemia da própria experiência, quando não consegue evidenciar a pluralidade de determinadas questões, deixando de fora toda a complexidade e as implicações de eventos da magnitude do holocausto. Assim mostraremos que Exil Shanghai enriquece a experiência, embora mostre limitações, enquanto Shanghai Ghetto condensa e banaliza as imagens e a história. Parafraseando Gilles Deleuze, consideramos que essas 'folhas do passado', narradas nas produções elencadas, são, de acordo com o autor em questão, "dreams and nightmares, ideas and visions, impetuses and actions of the subjects involved, while the givens of the situation merely contained causes and effects against which on could only struggle"5. Dessa forma, as imagens nesses filmes aparecem como tentativa de representação fragmentada de um passado reinventado.

A escolha das duas produções justifica-se pela intenção de fuga à obviedade. Nas últimas décadas, a sétima arte encontrou, em questões judaicas, um filão a ser explorado. Documentários e até filmes mais comerciais (no sentido de serem filmes populares, como os blockbusters, de entretenimento mais fugaz) abordaram temas como a Shoah (genocídio de judeus, na Segunda Guerra Mundial). Neste artigo, a intenção foi buscar obras que se destacassem não só pela temática, mas, especialmente, pela representação de visões distintas, que fugissem àquelas que, habitualmente, são mobilizadas academicamente.

Ademais, a questão que se coloca aqui é como a composição de dois documentários/filmes/obras de arte sobre o mesmo tema pode caminhar para

\footnotetext{
3 "Shanghai Ghetto" é um documentário histórico de Dana Janklowicz-Mann e Amir Mann, estreado em 2002. A história é narrada através das lembranças de antigos refugiados, dois dos quais acompanham os diretores por Shanghai, servindo-lhe como guias na cidade.

4 "Exil Shanghai" é um documentário de Ulrike Ottinger, de 1997. Constitui-se de seis histórias de judeus alemães, austríacos e russos, todos buscando refúgio em Shanghai. Suas histórias, fotos e documentos, combinados com imagens atuais da metrópole, compõem o filme.

${ }^{5}$ Gilles Deleuze, Cinema 1: a imagem-movimento, São Paulo, Brasiliense, 1985, p. 160.
} 
lados distintos: uma, acreditamos, acata uma linha mais banalizada da imagem; e a outra, apesar de informar menos ou de mostrar somente um ponto de vista (o do testemunho), abre mais as possiblidades artísticas do diálogo e da apresentação de um tema controverso como a memória/testemunho do holocausto.

\section{Shanghai Ghetto: abuso de imagens e faction}

Em seu ensaio "What does 'Coming to Terms with the Past' Mean?", Adorno discute o que seria um verdadeiro trabalho psicanalítico de buscar o passado e fazer uma autorreflexão crítica do que simplesmente "turning the page". Essa ideia de realmente enfrentar o problema, de tentar acessar um passado traumático, tanto para a população alemã quanto para os judeus, é banalizada, acreditamos, no documentário Shanghai Ghetto. A repetição, o abuso (entendido como um excesso) de imagens de arquivo (especialmente de reportagens do período histórico em questão), mescladas a gravações atuais, além de dois rasos depoimentos de sobreviventes, parecem ter o intuito de chocar, pois não resultam em uma autorreflexão crítica, nem da Shoah, nem da história dos judeus em Shanghai.

Em um dos depoimentos mobilizados no filme, Harold Janklowicz, pai de um dos cineastas, rememora momentos difíceis. Sempre comedido em sua fala, sr. Janklowicz lembra-se de ter chegado a Shanghai aos oito anos de idade, acompanhado de sua mãe, tendo encontrado um mundo estranho, repleto de pobreza e miséria. Sua mãe encontrou trabalho fazendo chapéus de senhoras, e ele chegou a frequentar escolas mantidas pela comunidade judaica local. $\mathrm{O}$ aspecto mais chocante do testemunho advém das lembranças da violência quase diária, sofrida por Janklowicz. Anos depois, Harold se viu novamente frente a frente com seu algoz, um colega de escola russo. No filme, ele revela que, ao final da guerra, retornou ao educandário com dois amigos e quase espancou o russo até a morte.

Quanto às imagens mobilizadas, há uma alternância, entre reportagens antigas e registros realizados pelos cineastas, que, munidos de uma câmera digital, foram até os guetos de Shanghai; muitos deles, inalterados desde a Segunda Guerra Mundial. Essa amálgama de imagens antigas e contemporâneas, depoimentos e fotos aparece no filme de maneira crua, documental, sem reflexões mais aprofundadas, o que reforça o tom de uma produção que não vai muito além do registro de uma época, tornando a reflexão limitada.

Sendo assim, o filme está longe da noção adorniana de que a rememoração e o "working through", enquanto processos psicanalíticos, são essenciais para construir uma memória e responsabilidade coletiva: 
'Encarar os termos do passado' não implica em um trabalho sério de enfrentar o passado e nem a quebra de seu feitiço através de um ato de consciência clara. Ele sugere, ao contrário, um desejo de virar a página e, se possível, limpá-la da memória. A atitude de que tudo seria esquecido e perdoado por aqueles que foram injustiçados é expressa por aqueles que cometeram a injustiça ... Um quer se livrar do passado, com razão, uma vez que não se pode viver em suas sombras, e sabendo que não há um fim ao terror se a culpa e a violência só são restituídas, repetidas vezes, com culpa e violência... Mas tão erroneamente, já que o passado que deseja se esvair ainda está tão intensamente vivo... Deveríamos patologicamente nos queimar com o passado, enquanto uma pessoa saudável e realista está absorvida com o presente e com suas preocupações práticas? Isso seria se apropriar da moral do 'é tão bom como se nunca tivesse acontecido', escrito por Goethe, mas proferido pelo diabo em um ponto decisivo de Fausto para revelar seu princípio mais íntimo: a destruição da memória. A arte assassinada a ser enganada, mesmo a partir da única coisa que a nossa impotência pode conceder-lhes: a lembrança. ${ }^{6}$

A imagem, repetida e banalizada, dos corpos e campos de extermínio, destrói a tentativa de se acessar a verdadeira história. Vários documentários, com intuito de conduzir sentimentos e exaltar sensações, com o mesmo foco nazista da Propaganda, foram produzidos ao fim da Segunda Guerra. Em 1945, por exemplo, Frank Capra dirigiu o filme Here is Germany que teve o objetivo de convencer a população americana e mundial da maldade absoluta e da violência sem precedentes que os alemães empregaram na construção dos Campos de Extermínio. A partir dessa obscenidade de cenas e imagens, muito criticada por Lanzmann em Shoah, e usando e abusando do arquivo que estava sendo construído, da visão de corpos, ossos e "muçulmanos", o filme desconstruiu

${ }^{6}$ "“'Coming with the terms of the past' does not imply a serious working through of the past, the breaking of its spell through an act of clear consciousness. It suggests, rather, wishing to turn the page and, if possible, wiping it from memory. The attitude that it would be proper for everything to be forgotten and forgiven by those who were wronged is expressed by the party that committed the injustice... One wants to get free of the past, rightly so, since one cannot live in its shadows, and since there is no end to terror if guilt and violence are only repaid, again and again, with guilt and violence... But wrongly so, since the past one wishes to evade is still so intensely alive... Should we it pathological to burden oneself with the past, while the healthy and the realistic person is absorbed in the present and its practical concerns? That would be to appropriate the moral from 'And it's as good as if it never happened' which is written by Goethe but uttered by the devil at a decisive point in Faust to reveal his innermost principle: the destruction of memory. The murdered arte to be cheated even out of the one thing that our powerlessness can grant them: remembrance." Theodor Adorno, What does coming to terms with the past mean? Bitburg in moral and political perspective, ed. Geoffrey H. Hartman, trans. Timothy Bahti and Geoffrey Hartman, Bloomington, Indiana University Press, 1986, p. 114-129, p. 115-117. 
a racionalidade e a sabedoria de uma nação com intuito de justificar a Guerra. O mesmo foi feito com a realização do filme Know your enemy: Japan, justificando, talvez, as bombas atômicas lançadas em Hiroshima e Nagasaki. Shanghai Ghetto, apesar de tentar contar a história dos judeus da China e não da Shoah, não foge a essa obsessão pela obscenidade da imagem, talvez pela sua aproximação com o cinema mais popular (aquele que se distancia de um cinema de arte mais filosófico e existencial).

Ao fazer referência ao holocausto, flashbacks sempre são resgatados: as imagens do Here is Germany, Erbkrank/The Hereditary Defective (Herbert Gerdes, 1936) e Alles Leben ist Kampf/All life is struggle (Herbert Gerdes, 1937) criaram um cenário para esse retorno contínuo de imagens/fotos de um passado traumático e mal compreendido. Cineastas e a filosofia popular não conseguem se desvincular mais desses marcos:

Se os flashbacks nos dão imagens de memória - os arquivos pessoais do passado - eles também nos dão imagens da história; do passado compartilhado e gravado. Na verdade, os flashbacks nos filmes muitas vezes fundem dois níveis de lembrança do passado, dando à história social e política o modo subjetivo de uma única experiência memorável de um indivíduo fictício. Esse processo pode ser chamado de 'memória subjetiva', o que aqui tem o duplo sentido de tornar a história como uma experiência subjetiva de um personagem na ficção, e a formação do sujeito na história como o espectador do filme identificando-se com personagens ficcionais inseridos em uma realidade social fictícia. ${ }^{7}$

Imagens modelam nosso pensamento, nossa visão do passado e nosso entendimento do que foi retratado através da banalização da imagem. "A close study of the variations in flashback is actually a means of questioning the conceptual foundations of history in relation to narrative and narrative in its relationship to history". De acordo com Deleuze, o flashback pode consumir o passado através da ação das imagens e isso se torna crucial na divisão entre o pré e o pós Segunda Guerra Mundial.

${ }^{7}$ If flashbacks give us images of memory, the personal archives of the past, they also give us images of history, the shared and recorded past. In fact, flashbacks in film often merge the two levels of remembering the past, giving large-scale social and political history the subjective mode of a single, fictional individual's remembered experience. This process can be called the "subjective memory," which here has the double sense of the rendering of history as a subjective experience of a character in the fiction, and the formation of the Subject in history as the viewer of the film identifying with the fictional characters positioned in a fictive social reality Maureen Turim, Flashbacks in Film: Memory and History, New York, Routledge, 1989, p. 2.

${ }^{8}$ Ibidem. 
Em Hollywood, esse lugar onde constantemente é forjado o senso comum, a "filosofia popular" de Gramsci, inicialmente, as produções se dividiam entre ficção e documentários. Porém, com a popularização do tema, a indústria televisiva e cinematográfica viu uma possibilidade de misturar fato, fascínio e ficção, ao realizar filmes e séries simplificados (e simplistas) sobre a 2. ${ }^{\text {a Guerra9} .}$ Assim "in their reanimation of the past, these films speak in a language that appeals to the broadest possible audiences, thus leaving themselves open to the criticism of at least simplifying and even of falsifying history"10.

O termo faction, que seria a junção dos termos fact and fiction (fato e ficção), foi publicado pela primeira vez por Antony Beevor na Revista Debat, em 2011. A ideia seria discutir e polemizar a questão do fato, relacionado à História, e da ficção, relacionada à qualquer tipo de representação dessa 'verdade' histórica. Segundo o pesquisador, existem inúmeros problemas quando a representação, através da literatura ou do cinema, almeja representar 'fatos reais', mas exagera na ficção: “à mon sens, la 'faction' ne pose problème que lorsque sont introduits de véritables personnages historiques et que l'on place des mots dans leurs bouches". ${ }^{11}$

Se, em um dado momento histórico, as produções visavam propagar as ideias dominantes, como foi o caso do cinema nazista e da Propaganda, hoje o grande apelo comercial acaba por enevoar uma tentativa de maior fidelidade aos fatos. Assim, recursos como a repetição de fotos, mostrando a pobreza que se vivia em Shanghai, e a banalização das imagens de arquivos da Shoah tornam-se o fio condutor de Shanghai Ghetto.

A fronteira entre fato e ficção é uma zona de um grande potencial comercial e não menos de uma grande corrupção potencial, em termos históricos. Nós temos assistido recentemente a um forte ajuntamento de ao que chamarei de «facção rampante» nos documentários como nas ficções. Uma das razões

\footnotetext{
${ }^{9}$ Neste sentido, temos, como exemplo paradigmático, A lista de Schindler (1993), de Steven Spielberg. Bem sucedida comercialmente, a produção foi acusada, pela argentina Beatriz Sarlo, de esvaziar o tema do Nazismo. A crítica cultural citou, em particular, a cena "de um banheiro com chuveiros em lugar de uma câmera de gás". A autora afirmou: "Se Spielberg não consegue fazer de sua cenografia algo verdadeiro e, também por isso, desmaterializa o holocausto, tampouco consegue captar minimamente a abundância simbólica do povo que forneceu suas vítimas". Beatriz Sarlo, Paisagens Imaginárias: Intelectuais, Arte e Meios de Comunicação, São Paulo, EDUSP, 2005, p. 51.

${ }^{10}$ Marcia Landy, Cinematic uses of the past, Minneapolis, University of Minnesota Press, 1996, p. 11.

${ }^{11}$ Antony Beevor, "La fiction et les facts: Perils de la "faction" in Le Débat, 2011/3, n. ${ }^{\circ} 165$, p. 31 .
} 
para estarmos envolvidos em um mundo pós-letrado onde a imagem animada é a rainha. ${ }^{12}$

Portanto, a exemplo do que ocorria no período dos filmes nazistas, em que a imagem era o grande destaque das representações e dos fenômenos de massa; no mundo contemporâneo, essa mesma imagem se torna ainda mais representativa e revisitada. Os filmes, desde o período nazista, evoluíram, mas ainda almejam atrair público e crítica, muitas vezes, através do choque e da espetacularização:

A necessidade de imagens impressionantes e de uma narrativa dinâmica tem submetido diretores a fortes tentações. E, claro, para a realização de documentários, a pressão bem das expectativas visuais e dramáticas alimentadas por filmes de ficção. O perigo é que a 'história do entretenimento' seja agora a principal fonte de conhecimento supostamente histórico para a maioria da população. A Histo-entretenimento, como os cínicos dizem, a ‘desviar-histórico', é superficial e falta conteúdo. Embora deforme o material, argumentam seus defensores, pelo menos dá um gosto da história. Mas uma rápida olhada sobre o legado de Hollywood vai mostrar, é um sofisma da pior espécie ${ }^{13}$.

Difamação, deformação da História, comercialização da imagem, não seriam esses os mesmos termos usados para definir o cinema nazista? Se, por um lado, a Literatura de Testemunho almeja estudar e entender o trauma de uma geração quase perdida, as produções contemporâneas de Hollywood, que se pretendem exercer a "função" de apresentar uma lição moral acerca das atrocidades nazistas, despertam o fetiche e a banalização da imagem de uma geração que não tem conteúdo histórico para questionar e refutar as representações

${ }^{12}$ Idem, Ibidem. La frontière entre fait et fiction est une zone d'un immense potentiel commercial, et d'une non moins grande corruption potentielle, en termes historiques. Nous avons assisté dernièrement à un fort accroissement de ce que j'appellerai la «faction rampante» dans les documentaires comme dans les fictions. Une des raisons en est que nous sommes entrés dans un monde post-lettré où l'image animée est reine.

${ }^{13}$ Le besoin d'images frappantes et d'une dynamique narrative a soumis les réalisateurs à de fortes tentations. Et, bien entendu, pour le tournage de documentaires, la pression vient des attentes visuelles et dramatiques alimentées par les films de fiction. Le danger est que l' «histoire divertissement» soit désormais la principale source de connaissance prétendument historique pour la majeure partie de la population. L'Histo-tainment, comme disent les cyniques, la 'divert-histoire', est à tout le moins superficielle et manque de tout contexte. Même si elle déforme le matériau, allèguent ses défenseurs, au moins donne-t-elle le goût de l'histoire. Or, un rapide coup d'œil sur l'héritage d'Hollywood le montrera, c'est un sophisme de la pire espèce. Antony Beevor, "La fiction et les facts...", cit., p. 32. 
hollywoodianas ${ }^{14}$. Heróis, histórias comoventes, superproduções de Guerra, que misturam documentos históricos, imagens de arquivo e personagens reais e inventados, povoam as salas de cinema e as televisões atualmente. Porém, para atrair maior público, a indústria do cinema e da televisão acaba por simplificar e idealizar o holocausto. Antes, os nazistas se utilizavam da Propaganda para reinventar a verdade; hoje, com essa simplificação, há, também, uma adulteração forçosa da História, característica da contemporaneidade.

As necessidades da indústria só podem perverter qualquer perspectiva histórica útil. A compulsão de fingir que um filme de Hollywood, de uma forma ou de outra, é verdade, mesmo que seja inteiramente uma fiç̧ão, é um fenômeno relativamente novo. No passado, os estúdios nunca teriam afirmado que os grandes filmes de guerra foram outra coisa senão uma boa história. Parece que agora o marketing alegando ser necessário essa autenticidade histórica. ${ }^{15}$

Usando imagens de arquivo e apresentando uma nota dizendo "baseado em fatos reais", essa nova linha de produção vende imagens e simplificações banais, recurso antigo e muito utilizado pelos nazistas.

Shanghai Ghetto não é um filme de Hollywood, mas comete os mesmos erros ao banalizar a imagem. A obra apresenta os testemunhos dos habitantes do gueto e de suas vidas em Shanghai, mas, paralelamente, parece tentar, de modo massivo, provar e confirmar o testemunho através das imagens, o que só enfraquece o documentário. A questão que se coloca, ao defendermos a tese do "enfraquecimento", tem como ponto nevrálgico a exploração excessiva de imagens, tendendo para um tom sensacionalista, e, não, reflexivo. Talvez, se as imagens (de destruição, sofrimento, desespero, pobreza) fossem acompanhadas de narrações reflexivas, se houvesse ponderações mais substanciais ao longo do filme, teríamos outra percepção.

${ }^{14}$ Uma discussão interessante sobre a banalização e o revisionismo histórico: Luis Nazario. "Revisionismo Bastardo em Tecnicolor", 2009 (http://escritorluiznazario.wordpress. com/2009/04/18/revisionismo-bastardo-em-glorioso-tecnicolor, consultado em 2016.09.12).

${ }^{15}$ Les besoins de l'industrie ne peuvent qu'infléchir toute perspective historique utile. La compulsion hollywoodienne à prétendre qu'un film, d'une façon ou d'une autre, est vrai, quand bien même il s'agit entièrement d'une fiction, est un phénomène relativement nouveau. Dans le passé, jamais les studios n'auraient prétendu que les grands films de guerre étaient autre chose qu'une bonne histoire. Il semble désormais, marketing oblige, qu'il faille revendiquer pour eux un caractère d'authenticité historique. Antony Beevor, "La fiction et les facts...", cit., p. 31. 


\section{Exil Shanghai: memória, fiç̧ão e testemunhos}

O filme Exil Shanghai, de coprodução Alemanha/Israel, ao longo de 275 minutos mostra o testemunho de seis ex-moradores de Shanghai, de diferentes camadas sociais e chegados em épocas e circunstâncias diversas. Estes seriam representantes da exótica comunidade judaico-chinesa, relatando suas experiências vividas na cidade. Reconstrução e recordação do passado, através das memórias ambíguas e vagas, construídas através da escavação derridiana do filme, dirigido por Ottinger.

Subversão seria a pauta da cinematografia dessa judia. Órfã e homossexual engajada, a diretora concentrou seus trabalhos em temas que procuram mostrar vias alternativas de representação. Na obra em questão, ela apresenta a subversão da condição masculina da cinematografia, adota e subverte a questão do documentário e também coloca em xeque a autoridade do testemunho:

Exil Shanghai adota e subverte as estratégias do documentário histórico ortodoxo. Em um aspecto, o filme apresenta um relato inquestionável e sem mediação da experiência de seis sobreviventes judeus que escaparam à perseguição em Xangai. Como argumenta o historiador feminista Joan W. Scott, a dependência da experiência de testemunhas oculares históricas (ou representantes culturais) na historiografia contemporânea (ou etnografia) tem sido uma espada de dois gumes. Por um lado, presume-se que o testemunho original dos sujeitos de textos históricos e etnográficos transmite o tipo de verdade mais autêntico. Tais testemunhos são citados em um esforço para incluir as perspectivas de mulheres, minorias ou representantes de outras culturas ou períodos históricos - e para melhorar os preconceitos e pontos cegos do pesquisador. Por outro lado, entretanto, a aceitação do testemunho ocular como fato, como reflexo de nada além do real, 'mascara o caráter necessariamente discursivo dessas experiências'. ${ }^{16}$

\footnotetext{
${ }^{16}$ Exil Shanghai both adopts and subverts the strategies of orthodox historical documentary. In one respect, the film presents an unquestioned and unmediated account of the experience of six Jewish survivor witnesses who escaped persecution in Shanghai. As feminist historian Joan W. Scott argues, reliance on the experience of historical eyewitnesses (or cultural representatives) in contemporary historiography (or ethnography) has been a double-edged sword. On the one hand, it is assumed that original testimony by the subjects of historical and ethnographic texts conveys the most authentic kind of truth. Such testimonies are cited in an effort to include the perspectives of women, minorities, or representatives of other cultures or historical periods - and to ameliorate the biases and blind spots of the researcher. On the other hand, however, acceptance of eyewitness testimony as hard fact, as a reflection of nothing but the real, 'masks the necessarily discursive character of these experiences'. Kirsten Harjes Tanja Nusser, “An Authentic Experience
} 
O próprio título do filme é uma subversão dos testemunhos. Ao narrar seus tempos no Ghetto Hongkew, e vivendo antes em bairros e comunidades judaicas, o que estaria em foco seria a Diáspora e não o Exílio. O exílio estaria relacionado a uma saudade, banzo da própria casa, e seria uma questão individual; já diáspora ${ }^{17}$ seria essa situação conjunta e permanente da própria condição judaica.

O que Ottinger nos proporciona é o enfraquecimento da autoridade da experiência através da arte visual. Embora Ottinger dê crédito ao testemunho de seus personagens, que narram suas experiências, também evidencia as imagens da atual China, recusando as imagens de arquivo. Assim, encontramos a diferença em relação aos tradicionais filmes sobre testemunhos. Enquanto Shanghai Ghetto usa imagens antigas, com o intuito de chocar o espectador, Exil Shanghai questiona essa autoridade:

Ao reconfirmar a autoridade da experiência através do uso de testemunhos não comentados, Exil Xangai simultaneamente enfraquece esta autoridade, entrelaçando a narrativa histórica do exílio judeu em Xangai durante a primeira metade deste século com um visual de / documentário' na vida cotidiana da rua em Xangai hoje. Esse entrelaçamento do passado e do presente chama a atenção para o caráter discursivo da experiência. Ottinger põe em xeque a autoridade dos depoimentos dos sobreviventes, evitando a técnica tradicional de apoiar as histórias orais com imagens de arquivo. Em vez disso, ela 'distrai' o espectador com um tour exploratório através da atual Shanghai, ocasionalmente mostrando a época do exílio judeu. ${ }^{18}$

of History: Tourism" in Ulrike Ottinger's Exil Shanghai", Women in German Yearbook, Nebraska, University of Nebraska Press, vol. 15 (1999), p. 247-263, p. 249.

${ }^{17}$ O cientista social Robin Cohen (1999), em seu trabalho mais influente Global Diasporas, observa quatro fases dos estudos da diáspora numa abordagem histórica, com intuito de interpretar os modos de livre circulação da massa migratória no contexto global e, sobretudo, a relação entre identidade e migração. Primeiramente, o uso clássico do termo diáspora, sempre no singular, designava unicamente a dispersão judaica. Dos anos 1960 aos 1970, o uso clássico foi se expandindo, e passou a designar também a dispersão grega, armênia, africana e irlandesa. Numa segunda fase, nos anos 1980, “diaspora was deployed as 'a metaphoric designation' to describe different categories of people - 'expatriates, expellees, political refugees, alien residents, immigrants and ethnic and racial minorities tout court"' (Cohen, 1999, p. 1). A terceira fase foi influenciada pelo ideário pós-moderno, cuja noção de identidade foi reordenada pela complexidade das concepções de desconstrução e desterritorialização. A quarta fase foi de consolidação "marked by a modified reaffirmation of the diasporic idea, including its core elements, common features and ideal types" (idem, p. 2).

${ }^{18}$ While reconfirming the authority of experience through the use of uncommented witness testimonies, Exil Shanghai simultaneously undermines this authority by intertwining the historical narrative of Jewish exile in Shanghai during the first half of this century with a visual 
Ottinger não é uma sobrevivente da Shoah, nem tampouco filha de sobrevivente. Ela se encontra numa categoria diferente, mas que teria talvez a autoridade de falar sobre este evento, uma vez que perdeu sua mãe na Guerra. Esse entrelugar - vítima/sobrevivente/órfã, lhe permite realizar esse amálgama de histórias de vida, retratadas através dos testemunhos e de imagens exóticas, capturadas na Shanghai dos dias atuais

Aqui, surge a ideia de que uma experiência autêntica da história é essencialmente uma experiência reflexiva derivada não de um conhecimento experiencial prefigurado por fontes históricas de arquivo, reencenações de eventos históricos ou artefatos e locais históricos 'intocados', mas de uma reflexão sobre a própria posição face às apresentações de história. ${ }^{19}$

Ao apresentar ao público imagens recentes de Shanghai, Ottinger não usa as técnicas tradicionais de documentários, mas também não as perde completamente, já que, em alguns furtivos momentos, mostra imagens de ruínas de prédios que sustentam as narrativas sobre a diáspora judaica em Shanghai.

Ao sobrepor memória antiga e imagens atuais, o "mal de arquivo" pessoal dos sobreviventes em Shanghai ao "mal de arquivo" da própria diretora, com suas próprias impressões da Shanghai atual, constrói-se "a film of 'live' memory in a rhythm of the future's ground" ${ }^{20}$. Estaríamos em um espaço aterritorial, de acordo com Derrida, que proporciona "the feeling inspired by this excessive and ultimately gratuitous investment in a perharps useless archive"21. Esse encontro entre passado e presente, talvez essa subversão da memória e do arquivo, conduz o espectador: "the viewer sees not as a distant observer, not through the lens of authoritative interpretation or an impealizing aestheticism, but rather as the

"documentary" on everyday street life in Shanghai today. This intertwining of past and present draws attention to the discursive character of experience. Ottinger challenges the authority of the survivors' testimonies by eschewing the traditional technique of supporting the oral histories with archival footage. Instead, she "distracts" the viewer with an exploratory tour through present-day Shanghai, only occasionally zooming in on ruinous building facades that bear evidence of the time of Jewish exile. Idem, p. 250.

${ }^{19}$ Here, it appears in the idea that an authentic experience of history is essentially a reflexive experience derived not from an experiential knowledge prefigured by archival historical sources, reenactments of historical events, or 'untouched' historical artifacts and sites, but from a reflection on one's own position vis-à-vis the presentations of history. Idem, p. 249.

${ }^{20}$ Amy Villarejo, “A Lesbian Impression of/in Ulrike Ottinger's 'Exile Shanghai'”, New German Critique, Duke University Press, n. ${ }^{\circ}$ 87, Special Issue on Postwall Cinema (Autumn, 2002), p. 157-191, p. 181.

${ }^{21}$ Jacques Derrida, Archive Fever: a Freudian impression, Trans. Eric Prenowitz, Chicago, University of Chicago Press, 1995, p. 12. 
exiles have seen. We reauthorize their misrecognitions in our own" 22 . Assim nos é mostrado o estranhamento em relação à vida judia na China, o estranhamento da tentativa de entendimento da diáspora e dos próprios limites do testemunho. As limitações da imagem, da fotografia e da palavra.

Ao trabalhar com a questão do turismo, Ottinger nos coloca como espectadores e turistas dessas histórias e testemunhos que nos são estranhas. Passado e presente, testemunho e imagem, ficção e realidade são contrastadas e subvertidas a todo momento. Se por um lado o turismo transforma o genuíno, autêntico e que é capaz de transmitir emoção e experiência sensorial em algo superficial, empobrecedor e estrangeiro, por outro lado esse mesmo turismo, enfatizado por Ottinger, é capaz de demonstrar a passagem do tempo, serve para atestar um artefato histórico como autêntico. Assim é visto Shanghai: um artefato histórico, hoje lugar de visita e contemplação, da presença judaica testemunhada pelos personagens do filme.

Shanghai mostrada é a cidade vista pelo olhar do oriente, pelo próprio olhar estrangeiro da diretora, assim como qualquer leitor/receptor de um testemunho é um estranho e um estrangeiro do que um dia aconteceu além dos limites da linguagem. Ao utilizar as técnicas de documentário, esperávamos que as imagens apresentadas fossem corroborar (ou banalizar) com os testemunhos, o que não acontece. Ao fazer essa subversão, acreditamos que Ottinger esteja querendo nos mostrar que tanto as imagens de arquivo, quanto as suas próprias imagens de Shanghai dos anos 90, não nos mostram (ou provam) nada da 'verdadeira' história. Os limites da linguagem, também, seriam os limites de representação e banalização da imagem. Exotismo, estranhamento, distância, passado inapreensível e presente ininteligível são questões levantadas pelo filme. A diretora nos coloca na posição de espectadores de um mundo exótico e de um tempo distante (e talvez surreal), ao mostrar tanto os testemunhos quanto as paisagens da China.

Ottinger, em outras palavras, recusa a autoridade do passado como convenção (fotografias antigas, mapas), mas também recusa a continuidade do presente como identidade (nós, judeus, então e agora). Um diferente alinhamento ético está em ação, uma codificação diferente do valor afetivo na disjunção que dá testemunho do que não pode ser apreendido e, em vez disso,

${ }^{22}$ Amy Villarejo, “A Lesbian Impression of/in Ulrike Ottinger's 'Exile Shanghai”, New German Critique, Duke University Press, No. 87, Special Issue on Postwall Cinema (Autumn, 2002), p. 157-191, p. 183. 
encontra o reconhecimento através de um desvio. A câmera de Ottinger registra a possibilidade de erro ao invés de endossar a ortodoxia de uma posição. ${ }^{23}$

Fotografar turisticamente seria uma forma de sacralização da imagem e pode ser relacionado à figura do sobrevivente. O testemunho, hoje, torna-se um mito, quase uma figura mitológica. Talvez esteja sendo dessacralizada pelo filme de Ottinger, acreditamos, mas ainda continua exaltada por outros documentários e filmes, como é o caso do Ghetto de Shanghai. Ao registrar mecanicamente, Ottinger estaria propositalmente desmistificando a figura do testemunho, já que imagem e palavra estão desconectadas.

\section{Considerações finais}

A superexposição de imagens de arquivo, em Shanghai Ghetto, introduz uma ausência e é capaz de evidenciar a presença da morte na imagem, mas banaliza a questão da Shoah. Também, ao transformar o olhar de quem fotografa, aponta diretamente para um mundo novo, e produz o distanciamento desse novo mundo já morto. "O poder fascinante da fotografia tende a certa ausência, à distância que ela introduz na experiência imediata do ambiente onde nada é visível. Ao colocar as coisas à distância, em sua impressionante ausência, a fotografia os faz objetos de desejo e de nostalgia" ${ }^{24}$. Sadismo, desejo e adulteração: assim é a subversão de filmes que utilizam imagens do arquivo da Shoah para modelar um tempo além de qualquer representação e poesia.

Em sentido diverso, as atuais ruínas da vida judia em Shanghai, apresentadas em Exil Shanghai, atestariam a passagem do tempo: a imagem como arquitetura de um tempo desgastado pela memória individual e coletiva. As fachadas do gueto judaico, dos prédios e ruas, representam um tempo transitório, falseado pela memória e pelo testemunho. Para Ottinger, uma experiência histórica legítima parece ser uma experiência do próprio tempo que revela a verdade escondida e conserva um passado que esvai. $\mathrm{O}$ testemunho tem esse caráter

${ }^{23}$ Ottinger, in other words, refuses the authority of the past as convention (old photographs, maps) but similarly refuses the continuity of the present as identity (we, Jews, then and now). A different ethical alignment is at work, a different coding of affective value, in the disjunction that gives testimony to that which cannot be grasped and instead finds recognition through a swerve. Ottinger's camera records the possibility of mistake rather than endorsing the orthodoxy of a position. Ibidem.

${ }^{24}$ Susan Sontag, Sobre fotografia, Tradução Rubens Figueiredo, São Paulo, Companhia das Letras, 2004, p. 26. 
antagônico de revelar uma experiência individual e coletiva, escondidas, e tentar resgatar um passado que se esvai, não memorável, narrável e apreensível.

O que seria, portanto, uma experiência histórica autêntica? Seria uma tentativa inescrupulosa, espetacularizada, como nos filmes hollywoodianos e documentários sensacionalistas das grandes redes televisivas? Ou uma subversão da autoridade testemunhal e da tentativa de chegar à verdade histórica, conforme ocorre em Exil Shanghai?

O questionamento não deve ser sucedido por respostas (dada à impossibilidade das mesmas), mas, por uma reflexão: a de que representações de um mesmo momento são contraditórias, artísticas e perturbadoras. Encantam e abrem possibilidades, mas podem também limitar e modelar o pensamento e a História. 